\title{
Plasma insulin, serum lipids and lipoproteins in gall stone disease in non-insulin dependent diabetic subjects: a case control study
}

\author{
M Laakso, M Suhonen, R Julkunen, K Pyörälä
}

\begin{abstract}
Fasting insulin, lipids and lipoproteins were measured in $\mathbf{2 2}$ middle aged female non-insulin dependent diabetics with gall stone disease (cases) and in 22 non-insulin dependent diabetics without gall stone disease (controls). The groups were matched for sex, age, obesity, and fasting glucose concentrations. No differences were observed between the cases and controls in duration of diabetes, glycated haemoglobin $A_{1}$, alcohol intake, smoking, use of cardiovascular drugs or a history of myocardial infarction. Diabetics with gall stone disease had higher fasting insulin concentrations $(p<0.5)$, lower total $(p<0.01)$ and low density lipoprotein cholesterol $(p<0.01)$ and high density lipoprotein cholesterol (not statistically significant) concentrations than diabetics without gall stone disease. These changes in insulin, lipids and lipoproteins are similar to reported changes in non-diabetic subjects with gall stone disease. Therefore, they are characteristic for gall stone disease and not as such explanatory to an increased risk of gall stones in patients with non-insulin dependent diabetes.
\end{abstract}

Numerous studies have confirmed the clinical impression that gall stones occur more frequently among obese than normal weight subjects). ${ }^{1-3}$ Because patients with non-insulin dependent diabetes are often obese this population is a a high risk in developing gall stones although the higher frequency of gall stone disease in diabetes has remained controversial. ${ }^{3+}$ Lipid abnormalities associated with non-insulin dependent diabetes favouring the development of gall stones are of particular interest in this respect. No studies have, however, been published on lipids and lipoproteins in patients with non-insulin dependent diabetes and with gall stone disease compared with patients with noninsulin dependent diabetes and without gall stone disease. In non-diabetic subjects, increased plasma insulin values, high serum triglyceride and low total and HDL cholesterol concentrations have been associated with gall stone disease..$^{5.8}$ Whether or not these changes in insulin, lipid and lipoprotein concentrations are associated with gall stone disease also in patients with non-insulin dependent diabetes are largely unknown. We, therefore, carried out a case control study in order to investigate the relationship between fasting plasma insulin, serum lipids, and lipoproteins in patients with non-insulin dependent diabetes with and without gall stone disease.

\section{Methods}

\section{PATIENTS}

The subjects were 22 middle aged non-insulin dependent diabetics with gall stone disease and 22 non-insulin dependent diabetics without gall stone disease. All subjects were women and fulfilled the WHO criteria of diabetes mellitus. ${ }^{9}$ Patients treated with diet only or with oral drugs were studied in order to exclude patients with insulin dependent diabetes. The subjects were randomly drawn from a large study investigating the prevalence of atherosclerotic vascular disease and its risk factors in non-insulin dependent diabetes. ${ }^{10}$ Only women were studied because of sex difference in serum lipids and lipoproteins and in the occurrence of gall stone disease. The study was based on a case control design. The pairs were matched for sex, age, obesity (measured by body mass index, BMI) and fasting glucose concentration in order to control the effects of these variables on plasma insulin, serum lipids, and lipoproteins.

Table I shows the characteristics of the cases and the controls. No difference between the groups was found with respect to age, body mass index, duration of diabetes, fasting plasma glucose, glycated haemoglobin $A_{1}$, use of oral hypoglycaemic drugs, alcohol intake (patient's own estimate transformed to absolute alcohol in grams/week), smoking, use of cardiovascular drugs and a history of myocardial infarction. In 11 diabetic patients the diagnosis of gall stone disease had been made before and in 11 patients after the diagnosis of diabetes.

\section{DIAGNOSIS OF GALL STONE DISEASE}

The diagnosis of gall stone disease was verified on the basis of medical records showing either a history of cholecystectomy or a diagnosis of gall stone disease based on cholecystography or ultra-

TABLE I Characteristics of the study population

\begin{tabular}{|c|c|c|}
\hline & Controls & Cases \\
\hline $\begin{array}{l}\text { Subjects }(\mathrm{n}) \\
\text { Age }(\mathrm{yrs}) \\
\text { BMI }\left(\mathrm{kg} /(\mathbf{m})^{2}\right) \\
\text { Duration of diabetes (yrs) } \\
\text { P-glucose (mmol/l) } \\
\text { GHbA }(\%) \\
\text { Alcohol intake (g/week) } \\
\text { Use of oral hypoglycaemic drugs }(\%) \\
\text { Current smokers }(\%) \\
\text { Use of betablockers }(\%) \\
\text { Use of diuretics }(\%) \\
\text { History of myocardial infarction }(\%)\end{array}$ & $\begin{array}{ll}22 & \\
58 \cdot 7 & (0 \cdot 9) \\
30 \cdot 7 & (1 \cdot 1) \\
8 \cdot 7 & (0 \cdot 9) \\
12 \cdot 0 & (0 \cdot 9) \\
10 \cdot 1 & (0 \cdot 4) \\
10 \cdot 0 & (10 \cdot 0) \\
68 \cdot 2 & \\
9 \cdot 1 & \\
40 \cdot 9 & \\
36 \cdot 4 & \\
0 & \end{array}$ & $\begin{array}{l}22 \\
58.9(1 \cdot 0) \\
31 \cdot 2(1 \cdot 3) \\
8.0(0 \cdot 8) \\
12.4(0 \cdot 9) \\
9.9(0 \cdot 4) \\
4.4(3 \cdot 3) \\
63.6 \\
13.6 \\
36.4 \\
63.6 \\
9.1\end{array}$ \\
\hline
\end{tabular}

Results are given as mean (SEM) with the exception of prevalence estimates which are expressed as percentages. $\mathrm{BMI}=$ body mass index; $\mathrm{GHbA}_{1}=$ glycated haemoglobin $\mathrm{A}_{1}$. 
sound investigation. All diabetic patients forming the control group underwent an ultrasound investigation (Aloka Fansonic 190 with a convex probe operating at $3.5 \mathrm{MHz}$ ). All patients fasted at least eight hours before the examination. Only those whose ultrasound investigation excluded a gall stone disease were accepted for controls. Altogether 10 patients primarily selected as controls had symptomless gall stone disease and they were therefore excluded from the final analyses.

\section{DETERMINATION OF BIOCHEMICAL PARAMETERS}

Serum lipids and lipoproteins were determined from fresh serum samples drawn after a 12 hour overnight fast. Lipoprotein fractionation was carried out using ultracentrifugation and selective precipitation with modifications" to the method originally described by Havel et al..$^{12}$ All spinnings were done at $10^{\circ} \mathrm{C}$ using a Kontron TGA-65 ultracentrifuge (Kontron International, Switzerland). Serum samples were centrifuged at density $(d)=1.006(105000 \mathrm{~g}$, for 18 hours $)$, and very low density lipoprotein triglycerides $(d<1.006)$ were recovered as the top fraction. Total high density lipoprotein cholesterol was separated by spinning serum samples at $\mathrm{d}=1.063$ (105000 $\mathrm{g}$, for 18 hours). Low density lipoprotein cholesterol $(\mathrm{d}=1 \cdot 006-1 \cdot 063$, including intermediate density lipoprotein) was calculated as a difference between the bottom fractions. On average, the mean day-to-day variation in high density lipoprotein cholesterol measurements was $3 \cdot 3 \%$, and the daily variation was $0.95 \% . \mathrm{HDL}_{2}$ and $\mathrm{HDL}_{3}$ cholesterol subfractions were separated running total high density liproprotein cholesterol fraction at $\mathrm{d}=1 \cdot 125$ (105000 $\mathrm{g}$, for 40 hours) and the top and bottom fractions were isolated by the tube slicing technique. Cholesterol and triglycerides from the whole serum and from lipoprotein fractions were assayed by automated enzymatic methods (Boehringer-Mannheim, West Germany). Glycated haemoglobin $A_{1}$, normal range 5.5$8 \cdot 5 \%$; coefficient of variation $=6 \%$ ) was determined by commercial colum chromatography (Quick-Sep Fast Hemoblogin Test System, Isolab Inc, Akron, $\mathrm{OH}$ ) after incubation in $0.9 \%$ saline solution for 12 hours. Blood samples for plasma insulin assay were taken into chilled tubes. Plasma was separated immediately and the samples were stored at $-70^{\circ} \mathrm{C}$ until the assay. Fasting plasma insulin was determined by commercial double antibody solid phase radioimmunoassay (Phadeseph, Pharmacia Diagnostics, Sweden) with a detection limit of $2.5 \mathrm{mIU} / 1$ and the variation coefficient below $5 \cdot 0 \%$.

STATISTICAL ANALYSIS

The results are expressed as mean (SEM). The differences between the cases and the controls were assessed by Student's two-tailed $t$ test for paired data and by the $\chi^{2}$ test (uncontinuous variables). Logarithmic values for total triglycerides and fasting insulin concentrations were used in statistical analyses. The relationships between variables were calculated using Pearson
TABLE II Fasting plasma insulin ( $m U / l)$, serum total and lipoprotein cholesterol (mmol/l) and trigclycerides (mmol/l) in diabetics with (cases) and without gall stone disease (controls)

\begin{tabular}{|c|c|c|}
\hline & Controls & Cases \\
\hline Fasting plasma insulin & $22 \cdot 6 \quad(2 \cdot 3)$ & $30 \cdot 0 \quad(3 \cdot 3)^{\star}$ \\
\hline Total cholesterol & $7 \cdot 43(0 \cdot 28)$ & $6.51(0.28) \dagger$ \\
\hline HDL cholesterol & $1 \cdot 24(0.05)$ & $1.09(0.09)$ \\
\hline $\mathrm{HDL}_{2}$ cholesterol & $0.84(0.05)$ & $0.70(0.10)$ \\
\hline $\mathrm{HDL}_{3}$ cholesterol & $0.39(0.03)$ & $0.39(0.03)$ \\
\hline LDL cholesterol & $5.02(0.22)$ & $3.97(0.22) \dagger$ \\
\hline VLDL cholesterol & $1.17(0.09)$ & $1.45(0 \cdot 16)$ \\
\hline Total triglycerides & $2.46(0.25)$ & $2 \cdot 51(0.18)$ \\
\hline HDL triglycerides & $0.16(0.02)$ & $0 \cdot 16(0.02)$ \\
\hline LDL triglycerides & $0.47(0.04)$ & $0.44(0.04)$ \\
\hline VLDL triglycerides & $1.83(0.23)$ & $1.91(0.15)$ \\
\hline
\end{tabular}

Results are given as mean (SEM). Comparison between cases and controls by Student's paired $t$ test and $\chi^{*}$ test.

${ }^{\star} \mathrm{p}<0.05 ;$ tp $<0.01$

$\mathrm{HDL}=$ high density lipoprotein; $\mathrm{LDL}=$ low density lipoprotein; VLDL = very low density lipoprotein.

correlation coefficients. The comparison of more than two groups was performed by the analysis of covariance (ANCOVA) after adjustment for confounding factors.

\section{Results}

Table II shows plasma insulin, serum lipid and lipoprotein concentrations in cases and controls. Fasting plasma insulin was higher among patients with gall stone disease than among those without $(p<0.05)$. Cases had lower total and low density liproprotein cholesterol concentrations than controls. High density liproprotein and $\mathrm{HDL}_{2}$ cholesterol tended to be lower in cases than in controls but the difference was not statistically significant. Total triglycerides and triglyceride fractions were almost identical between the two groups. Seventeen of the cases had undergone cholecystectomy and five had a gall stone disease diagnosed by radiograph or ultrasound investigation.

Because cholecystectomy and the awareness of the diagnosis of gall stone disease could have had an influence of the results, lipid and lipoprotein concentrations were also compared between the following subgroups of patients: (i) diabetics with previously diagnosed gall stone disease who had undergone cholecystectomy (17); (ii) diabetics with previously diagnosed gall stone disease who had not been operated (five); (iii) diabetics with newly diagnosed gall stone disease (10 patients primarily selected as controls but excluded from all other analyses because of gall stone disease, see Methods). The cases of the study consist of groups $i$ and ii. As the three subgroups differed with respect to age, body mass index, fasting plasma glucose, alcohol intake and the use of diuretics, lipid and lipoprotein levels were adjusted for the effects of these factors (ANCOVA). No difference in adjusted means between these subgroups was seen in total cholesterol $(6.81,5.86$ and 6.60 $\mathrm{mmol} / \mathrm{l}$, respectively, $\mathrm{p}=\mathrm{NS}$ ) low density lipoprotein cholesterol $(4.12,3.75$ and $4.01 \mathrm{mmol} / \mathrm{l}$, respectively, $p=N S$ ), or in high density lipoprotein cholesterol $(1 \cdot 15,0.90$ and $1 \cdot 10 \mathrm{mmol} / \mathrm{l}$, respectively, $p=N S$ ). Neither did other cholesterol and triglyceride lipoprotein fractions differ between these three subgroups of patients.

Table III shows Pearson correlation coefficients between age, body mass index, alcohol 
TABLE III Pearson correlation coefficients between age, body mass index, alcohol intake, duration of diabetes, plasma glucose, glycated haemoglobin $A_{1}$, fasting plasma insulin and lipids and lipoproteins in diabetics with (cases) and without gall stone disease (controls).

\begin{tabular}{|c|c|c|c|c|c|c|c|c|}
\hline & $\begin{array}{l}\text { Controls } \\
\text { TOTC }\end{array}$ & $H D L C$ & $L D L C$ & $V L D L C$ & $T G$ & $H D L T G$ & $L D L T G$ & $V L D L T G$ \\
\hline $\begin{array}{l}\text { Age } \\
\text { BMI } \\
\text { Alcohol intake } \\
\text { Duration of diabetes } \\
\text { Plasma glucose } \\
\text { GHbA, } \\
\text { Fasting plasma insulin }\end{array}$ & $\begin{array}{l}0.060 \\
-0.258 \\
-0.157 \\
-0.253 \\
0.643 \\
0.383^{\star} \\
0.029\end{array}$ & $\begin{array}{l}-0 \cdot 112 \\
-0 \cdot 418^{\star} \\
-0 \cdot 185 \\
0 \cdot 117 \\
0 \cdot 148 \\
0 \cdot 144 \\
-0 \cdot 469^{\star}\end{array}$ & $\begin{array}{c}0.068 \\
-0.337 \\
-0.238 \\
-0 \cdot 281 \\
0.546 \dagger \\
0.251 \\
0.083\end{array}$ & $\begin{array}{c}0 \cdot 084 \\
0 \cdot 278 \\
0 \cdot 204 \\
-0 \cdot 155 \\
0 \cdot 527^{\star} \\
0 \cdot 456^{\star} \\
0 \cdot 166\end{array}$ & $\begin{array}{c}0.193 \\
0.255 \\
-0.004 \\
-0.019 \\
0.403^{\star} \\
0.296 \\
0.174\end{array}$ & $\begin{array}{r}0.223 \\
0.251 \\
-0.145 \\
-0.018 \\
0 \cdot 197 \\
0 \cdot 111 \\
0.320\end{array}$ & $\begin{array}{c}-0 \cdot 244 \\
-0 \cdot 089 \\
0 \cdot 011 \\
-0 \cdot 386^{\star} \\
0 \cdot 394^{\star} \\
0 \cdot 287 \\
0 \cdot 316\end{array}$ & $\begin{array}{l}0 \cdot 237 \\
0 \cdot 277 \\
0 \cdot 003 \\
0 \cdot 044 \\
0 \cdot 364^{\star} \\
0 \cdot 270 \\
0 \cdot 117\end{array}$ \\
\hline
\end{tabular}

\begin{tabular}{|c|c|c|c|c|c|c|c|c|}
\hline & $\begin{array}{l}\text { Cases } \\
\text { TOTC }\end{array}$ & $H D L C$ & $L D L C$ & $V L D L C$ & $T G$ & $H D L T G$ & $L D L T G$ & $V L D L T G$ \\
\hline $\begin{array}{l}\text { Age } \\
\text { BMI } \\
\text { Alcohol intake } \\
\text { Duration of diabetes } \\
\text { Plasma glucose } \\
\text { GHbA } \\
\text { Fasting plasma insulin }\end{array}$ & $\begin{array}{r}0.220 \\
-0.014 \\
0.107 \\
-0.012 \\
-0.345 \\
-0.086 \\
-0.068\end{array}$ & $\begin{array}{c}0.115 \\
-0.450^{\star} \\
0.364^{\star} \\
0.119 \\
-0.336 \\
-0.176 \\
-0.395^{\star}\end{array}$ & $\begin{array}{r}0 \cdot 500 \dagger \\
-0 \cdot 016 \\
0 \cdot 110 \\
0 \cdot 216 \\
-0 \cdot 210 \\
-0 \cdot 109 \\
-0 \cdot 274\end{array}$ & $\begin{array}{c}-0.355 \\
0.244 \\
-0 \cdot 161 \\
-0.378^{\star} \\
-0 \cdot 135 \\
0.094 \\
0.468^{\star}\end{array}$ & $\begin{array}{r}-0.218 \\
0.296 \\
-0.213 \\
-0.274 \\
0.079 \\
0.191 \\
0.363^{\star}\end{array}$ & $\begin{array}{c}-0 \cdot 364^{\star} \\
0 \cdot 275 \\
0.050 \\
-0 \cdot 289 \\
-0 \cdot 011 \\
0 \cdot 008 \\
0 \cdot 290\end{array}$ & $\begin{array}{c}-0.139 \\
0.442^{\star} \\
-0.217 \\
-0.257 \\
-0.011 \\
-0.047 \\
0.368^{\star}\end{array}$ & $\begin{array}{r}-0.177 \\
0.205 \\
-0.205 \\
-0.224 \\
-0.095 \\
0.238 \\
0.301\end{array}$ \\
\hline
\end{tabular}

${ }^{\star} \mathrm{p}<0.05 ; \mathrm{tp}<0.01$

${ }^{\star} \mathrm{p}<0.05 ; \mathrm{tp}<0.01$ low density lipoprotein cholesterol; TG =triglycerides; HDLTG=high density lipoprotein triglycerides; $L D L T G=$ low density lipoprotein triglycerides; VLDLTG=very low density lipoprotein triglycerides; $B M I=$ body mass index; $\mathrm{GHbA}_{1}=$ glycated haemoglobin.

intake, duration of diabetes, fasting glucose, glycated haemoglobin $A_{1}$, fasting insulin and lipids and lipoproteins in cases and controls. Age was correlated positively with low density lipoprotein cholesterol and negatively with very low density lipoprotein cholesterol in cases but not in controls. Body mass index correlated inversely with high density lipoprotein cholesterol in both groups and with low density lipoprotein triglycerides in cases. Alcohol intake correlated positively with high density lipoprotein cholesterol in cases. Duration of diabetes correlated negatively with low density lipoprotein triglycerides in controls and with very low density lipoprotein cholesterol in cases. Fasting glucose was positively correlated with total and low density lipoprotein cholesterol in controls, but not in cases. In controls, plasma glucose correlated significantly also with very low density lipoprotein cholesterol, total triglycerides, low density lipoprotein triglycerides, and very low density lipoprotein triglycerides. Glycated haemoglobin $A_{1}$ correlated positively with total and very low density lipoprotein cholesterol in controls. Fasting insulin had strong inverse correlation with high density lipoprotein cholesterol in both groups and a positive correlation with very low density lipoprotein cholesterol, total and low density lipoprotein triglycerides in cases.

\section{Discussion}

Our study based on a case control design in female non-insulin dependent diabetics showed that diabetics with gall stone disease had lower total and low density lipoprotein cholesterol than diabetics without gall stone disease. Lower total and low density lipoprotein cholesterol concentrations were not related to a history of cholecystectomy because no significant difference in cases in total and low density lipoprotein cholesterol was observed between those who had been operated and those who had not been operated. A statistically non-significant trend for lower high density lipoprotein and $\mathrm{HDL}_{2}$ choles- terol in cases was seen compared to controls but total triglycerides were similar in both groups. Diabetics with gall stone disease had higher fasting plasma insulin than those without gall stone disease.

The only study measuring lipids and lipoproteins and fasting insulin in subjects with and without gall stone disease is the study of Scragg et al..$^{5}$ They measured fasting plasma lipid and insulin concentrations in 173 non-diabetic patients with gall stones and 284 hospital controls. Increased plasma insulin was associated with an increased risk of gall stones in both sexes. Total and high density lipoprotein cholesterol were associated inversely and total triglycerides positively with the risk of gall stone disease. Our findings in patients with non-insulin dependent diabetes are quite similar; gall stone disease was related to high insulin and low total, low density lipoprotein and high density lipoprotein cholesterol.

The association of gall stone disease with low total cholesterol is of particular interest because it has also been reported in other studies. ${ }^{56}$ In previous studies low density lipoprotein cholesterol has not been measured. The lowering of total cholesterol in our patients was due to the lowering of low density lipoprotein cholesterol fraction. Lowered low density lipoprotein cholesterol might be a manifestation of a decreased rate of apo low density lipoprotein (corresponding to apolipoprotein B of low density lipoprotein ${ }^{4}$ synthesis. ${ }^{13}$ Decreased apo low density lipoprotein synthesis would result in a decreased cholesterol efflux from the liver into blood with a concomitant increase in cholesterol secretion into bile. Indeed, as can be calculated from the data of Grundy et al,${ }^{14}$ lower plasma cholesterol levels and higher biliary cholesterol output are characteristic features of southwestern American Indian women with cholesterol gall stones as compared with those without. None of the control group had diabetes but seven of the 22 gall stone patients had noninsulin dependent diabetes. On the other hand, in white women with gall stones blood (plasma or 
serum) concentrations of cholesterol may be age dependent. Women with gall stones and under the age of 50 years tended to have higher cholesterol concentrations than the controls whereas women with gall stones and over 50 years of age have had lower concentrations than their controls. ${ }^{515}$ This is in accordance with the findings of our study. Low levels of total and low density lipoprotein cholesterol in patients with gall stone disease, however, would be at least in part related to the modification of their life styles, particularly to those related to diet. Lower intake of dietary saturated fat could lead to lowering of total and low density lipoprotein cholesterol as shown by several studies. ${ }^{16}$

Like Scragg et $a l^{5}$ we also found that patients with gall stone disease had higher fasting insulin concentrations than those without. Similar results have been reported in other studies, ${ }^{17} 18$ too. Non-insulin dependent diabetes is characterised by obesity and insulin resistance and raised fasting insulin concentrations in noninsulin dependent diabetes is an indication of insulin resistance. In insulin resistant states a positive correlation between obesity and insulin level is usually seen. In addition, high insulin concentration is associated positively with total triglyceride concentration and negatively with high density lipoprotein cholesterol concentration. ${ }^{19}$ In our study populations we also found a consistent positive correlation between insulin and body mass index, and a negative correlation between insulin and high density lipoprotein cholesterol. On the basis of these results it can be concluded that insulin resistance is a powerful risk factor for gall stone disease among patients with non-insulin dependent diabetes. This hypothesis is supported by an extraordinary high frequency of gall stone disease in Pima Indians having high concentrations of fasting insulin and marked insulin resistance. ${ }^{20}$ Mechanisms by which hyperinsulinaemia could induce gall stone formation are largely unknown. High insulin concentrations can, however, activate low density lipoprotein receptors ${ }^{21}$ which enhance low density lipoprotein cholesterol transport from blood into the liver. This could decrease low density lipoprotein cholesterol concentration in serum and hepatocytes would then increase cholesterol output into bile. As a matter of fact, those non-insulin dependent diabetics with highest fasting plasma insulin concentrations have reported to have lowest plasma low density lipoprotein cholesterol concentrations. ${ }^{22}$

In conclusion, our study shows that high fasting insulin, low total and low density lipoprotein cholesterol as well as a tendency to low high density lipoprotein and $\mathrm{HDL}_{2}$ cholesterol level are characteristic for non-insulin dependent diabetics with gall stone disease as compared with corresponding diabetics without gall stones the findings are related to gall stone disease itself. Our results suggest that mere changes in plasma insulin, serum lipid and lipoprotein levels in non-insulin dependent diabetics with gall stones do not account for increased prevalence of gall stone disease in noninsulin dependent diabetes. The role of other possible factors, such as the function of gall bladder, for instance, remains to be determined.

1 Friedman GD, Kannel WB, Drawber TR. The epidemiology of gallbladder disease: observations in the Framingham Study. F Chronic Dis 1966; 19: 273-92.

2 Mabee TM, Meyer P, BenBester L, et al. The mechanism of increasing gallstone formation in obese human subjects. Surgery 1976; 79: 460-8.

3 Bennion LJ, Grundy SM. Risk factors for the development of cholelithiasis in man. N Engl f Med 1978; 299: 1221-7.

4 Yan R, Arem R, Chan L. Gastroinestinal tract complications of diabetes mellitus. Pathophysiology and management. Arch Intern Med 1984; 144: $1251-6$.

5 Scragg RKR, Calvert GD, Oliver JR. Plasma lipids and insulin in gallstone disease: a case-control study. $\mathrm{Br}$ Med $\mathcal{F} 1984$; 289: $521-5$.

6 Van der Linden W. Some biological traits in female gallstonedisease patients. Acta Chir Scand 1961; suppl 269: 1-94.

7 Pettiti DB, Friedman GD, Klatsky AL. Association of a history of gallbladder disease with a reduced concentration of high density lipoprotein cholesterol. N Englf Med 1981 304: 1396-8.

8 Ahlberg J. Serum lipid levels and hyperlipoproteinaemia in men with gallstone disease. Acta Chir Scand 1979; 145: 373-7.

9 World Health Organization Expert Committee on Diabetes Mellitus. Second report. Technical report series 646 . Geneva: World Health Organization, 1980.

10 Laakso M, Rönnemaa T, Pyöräta K, Kallio V, Puukka P, Penttilä I. Atherosclerotic vascular disease and its risk factors in noninsulin-dependent diabetic and nondiabetic subjects in Finland. Diabetes Care 1988; 11: 449-63.

11 Penttilä IM, Voutilainen E, Laitinen P, et al. Comparison of different analytical and precipitation methods for the direct estimation of serum high-density lipoprotein cholesterol. Scand f Clin Lab Invest 1981; 41: 353-60.

12 Havel RJ, Eder HA, Bragdon HJ. The distribution and chemical composition of ultracentrifugally separated lipoproteins in human serum. $\mathcal{F}$ Clin Invest 1955; 34: 1345-53.

13 Garnick MB, Bennett PM, Langer T. Low density lipoprotein metabolism and lipoprotein cholesterol content in Southwestern American Indians. $\mathcal{F}$ Lipid Res 1979; 20 : 31-9.

14 Grundy SM, Metzger AL, Adler RD. Mechanisms of lithogenic bile formation in American Indian women with cholesterol gallstones. $\mathcal{F}$ Clin Invest 1972; 51 : 3026-43.

15 Cavallini A, Messa C, Mangini V, Argese V, Misciagna G, Italo G. Serum and bile lipids in young women with radiolucent gallstones. Am f Gastroenterol 1987; 82: radiolucent

16 Lewis B, Mancini M, Puska P. Dietary measures for control of lipoprotein risk factors. In: Olsson AG, ed.Atherosclerosis, biology and clinical science. Edinburgh: Churchill Livingstone, 1987: 409-17

17 Stout RW, Bahner JP, Henry RW, Buchanan KD. Plasma lipids and gastrointestinal hormones in subjects with gallstones. Horm Metab Res 1978; 10: 357-8

18 Norton JJ, Smith LR, Hamper E. Diabetes mellitus and gallstones with special reference to insulin assay. Am f Gastroenterol 1968; 50: 214-20.

19 Laakso M, Pyörälä K, Voutilainen E, Marniemi J. Plasma insulin and serum lipids and lipoproteins in middle-aged non-insulin-dependent diabetic and non-diabetic subjects. Am f Epidemiol 1987; 125: 611-21.

20 Sampliner RE, Bennett PH, Comess LR, Rose FA, Burch TA. Gallbladder disease in Pima Indians. Demonstration of high prevalence and early onset by cholecystography. $N$ Engl prevalence and early ons

21 Chait A, Bierman EL, Albers JJ. Low-density lipoprotein receptor activity in cultured human skin fibroblasts mechanisms of insulin-induced stimulation. $\mathcal{f}$ Clin Invest 1979; 64: 1309-19.

22 Kissebah AH, Alfarsi S, Evans DJ, Adams PW. Plasma low density lipoprotein transport kinetics in noninsulin-dependent diabetes mellitus. 7 Clin Invest 1983; 71: 655-67. 